\title{
Hematology
}

\section{International sentinel site surveillance of patients with transfusional hemosiderosis treated with deferasirox in actual practice setting}

Amal El-Beshlawy, Baba Inusa, David Beneitez Pastor, Blanca Xicoy, Maria Soledada Duran Nieto, Andreas Bruederle, Amin Azmon, Geralyn Gilotti \& Mohsen Elalfy

To cite this article: Amal El-Beshlawy, Baba Inusa, David Beneitez Pastor, Blanca Xicoy, Maria Soledada Duran Nieto, Andreas Bruederle, Amin Azmon, Geralyn Gilotti \& Mohsen Elalfy (2019) International sentinel site surveillance of patients with transfusional hemosiderosis treated with deferasirox in actual practice setting, Hematology, 24:1, 238-246, DOI: 10.1080/16078454.2018.1558758

To link to this article: https://doi.org/10.1080/16078454.2018.1558758

(c) 2018 The Author(s). Published by Informa UK Limited, trading as Taylor \& Francis Group

曲 Published online: 17 Dec 2018.

Submit your article to this journal

山 Article views: 316

View Crossmark data $\nearrow$ 


\title{
International sentinel site surveillance of patients with transfusional hemosiderosis treated with deferasirox in actual practice setting
}

\author{
Amal El-Beshlawy ${ }^{a}$, Baba Inusa ${ }^{b}$, David Beneitez Pastor ${ }^{\text {C }}{ }^{c}$, Blanca Xicoy ${ }^{d}$, Maria Soledada Duran Nieto ${ }^{e}$, \\ Andreas Bruederle, ${ }^{f}$ Amin Azmon ${ }^{f}$, Geralyn Gilotti ${ }^{g}$ and Mohsen Elalfy ${ }^{h}$ \\ ${ }^{a}$ Cairo University, Cairo, Egypt; ${ }^{\text {b Evelina Children's Hospital, Guy's and St Thomas' Hospital NHS Trust, London, UK; ' } H e m a t o l o g y}$ \\ Department, Hospital Universitari Vall d'Hebron, Barcelona, Spain; ${ }^{d}$ ICO-Badalona-Hospital Germans Trias i Pujol, Josep Carreras Leukemia \\ Research Institute, Barcelona, Spain; ${ }^{\circ}$ Departamento de Hematologíca, Hospital Materno Infantil de Jaen, Jaén, Spain; ${ }^{\mathrm{f}}$ Novartis Pharma AG, \\ Basel, Switzerland; ${ }^{9}$ Novartis Pharmaceuticals Corporation, East Hanover, NJ, USA; ${ }^{\mathrm{h}}$ Ain Shams University, Cairo, Egypt
}

\begin{abstract}
Objective: The study evaluates the long-term deferasirox treatment of adult and pediatric patients with chronic transfusional iron overload in clinical practice.

Methods: In this non-interventional study, patients were observed for up to 3 years from initiation of deferasirox treatment both prospectively and retrospectively for up to 1 year prior to enrollment. The primary end points were the proportion of patients with $\geq 1$ notable increase in serum creatinine ( $\mathrm{SCr}$ ), and $\geq 1$ notable increase in alanine aminotransferase (ALT). Results: Overall, 120 patients were enrolled and 51 completed the study, with a limited 3-year dropout rate of $12.5 \%$ due to adverse events (AEs). Increase in $\mathrm{SCr}>33 \%$ above baseline and the age-adjusted ULN (upper limit of normal) was observed in 14 patients $(95 \% \mathrm{Cl}, 7.1-19.2)$. The ALT levels $>5 \times$ ULN was observed in 1 patient. Most frequent AEs reported during treatment with deferasirox include gastrointestinal disturbances.

Conclusions: The long-term treatment with deferasirox was manageable in most transfusiondependent patients with no unexpected safety findings. Regular monitoring and an adjusted deferasirox dosing strategy per local labels allowed continued iron chelation treatment and control of transfusional iron in the majority of patients on study.
\end{abstract}

\section{KEYWORDS}

Deferasirox; iron overload; iron chelation therapy; safety

\section{Introduction}

Patients with thalassemia, sickle-cell disease (SCD), myelodysplastic syndromes (MDS), and other transfusion-dependent anemias require long-term red blood cell transfusions. Long-term iron chelation therapy is required in regularly transfused patients to manage chronic iron overload and associated risks [1-3]. Currently, three main iron chelators are available for clinical use: deferoxamine, deferiprone, and deferasirox. The once-daily oral deferasirox dispersible tablet formulation, available since 2005, offered an improved option with greater compliance over parenteral deferoxamine [3-6]. The efficacy and safety of deferasirox dispersible tablet have been well defined through an extensive clinical trial program in adult and pediatric patients with a variety of transfusion-dependent anemias in adult and pediatric patients aged $\geq 2$ years [7-11]. The present study reports the results of a post-marketing active surveillance program for deferasirox. The aim of the study was to evaluate the long-term safety and clinical management of deferasirox in adult and pediatric patients aged $\geq 2$ years with chronic transfusional iron overload in the actual practice setting.

\section{Materials and methods}

\subsection{Study design}

This was a global, non-interventional study (July 2011October 2015) conducted on 14 sites in four countries (Egypt, Jordan, Spain and UK). The data were collected for 3 years from the initiation of treatment with deferasirox $\left(\right.$ Exjade $\left.^{\oplus}\right)$. The registry did not impose a therapy protocol, diagnostic/therapeutic interventions, or a strict visit schedule. Patients were treated with deferasirox in clinical practice settings, at the discretion of the investigator, and as per local country prescribing information. Retrospective data were collected in patients who had treatment with deferasirox for up to 1 year prior to enrollment.

\subsection{Key inclusion/exclusion criteria}

Male or female patients aged $\geq 2$ years and treated with deferasirox for transfusional hemosiderosis in accord- 
Table 1. Demographics and baseline data by age group.

\begin{tabular}{|c|c|c|c|}
\hline Characteristics & $\begin{array}{c}<18 \text { years } \\
(n=69)\end{array}$ & $\begin{array}{c}\geq 18 \text { years } \\
(n=51)\end{array}$ & $\begin{array}{c}\text { All patients } \\
(n=120)\end{array}$ \\
\hline Mean age, years & 7.5 & 57.9 & 28.9 \\
\hline SD & 4.2 & 22.1 & 29.0 \\
\hline Female: Male, $n$ & $35: 34$ & $21: 30$ & $56: 64$ \\
\hline \multicolumn{4}{|l|}{ Race, $n(\%)$} \\
\hline Caucasian & 37 (53.6) & $44(86.3)$ & $81(67.5)$ \\
\hline Black & $21(30.4)$ & $6(11.8)$ & $27(22.5)$ \\
\hline Asian & $7(10.1)$ & $0(0.0)$ & $7(5.8)$ \\
\hline Native American & $0(0.0)$ & $1(2.0)$ & $1(0.8)$ \\
\hline Other & $4(5.8)$ & $0(0.0)$ & $4(3.3)$ \\
\hline \multicolumn{4}{|l|}{ Disease, $n(\%)$} \\
\hline$\beta$ thalassemia major & $34(49.3)$ & 7 (13.7) & $41(34.2)$ \\
\hline$\beta$ thalassemia intermedia & $7(10.1)$ & $1(2.0)$ & $8(6.7)$ \\
\hline Refractory anemia & $0(0.0)$ & $2(3.9)$ & $2(1.7)$ \\
\hline Sideroblastic anemia & $0(0.0)$ & $3(5.9)$ & $3(2.5)$ \\
\hline Myelodysplastic syndrome & $0(0.0)$ & $21(41.2)$ & $21(17.5)$ \\
\hline Diamond-Blackfan anemia & $2(2.9)$ & $0(0.0)$ & $2(1.7)$ \\
\hline Hemolytic anemia & $0(0.0)$ & $1(2.0)$ & $1(0.8)$ \\
\hline Sickle cell disease (SS or Sbeta zero or both) & $24(34.8)$ & $7(13.7)$ & $31(25.8)$ \\
\hline Other & $2(2.9)$ & $9(17.6)$ & $11(9.2)$ \\
\hline \multicolumn{4}{|l|}{ History of blood transfusions } \\
\hline Mean $\pm S D$, time since start of blood transfusions* (years) & $4.3 \pm 4.0$ & $8.7 \pm 12.9$ & $6.1 \pm 9.1$ \\
\hline Total number of blood transfusions received (median) & 33.0 & 29.0 & 30.0 \\
\hline \multicolumn{4}{|l|}{ Patients with prior chelation therapy, $n(\%)$} \\
\hline Deferoxamine & $17(24.6)$ & $12(23.5)$ & $29(24.2)$ \\
\hline Deferiprone & $23(33.3)$ & $3(5.9)$ & $26(21.7)$ \\
\hline Deferoxamine + deferiprone & 0 & $1(2.0)$ & $1(0.8)$ \\
\hline Deferasirox & $1(1.4)$ & $13(25.5)$ & $14(11.7)$ \\
\hline \multicolumn{4}{|l|}{ Duration of exposure to deferasirox } \\
\hline Median & 36.0 & 10.0 & 29.9 \\
\hline Mean & 30.6 & 15.1 & 23.9 \\
\hline
\end{tabular}

ance with the local prescription information, patients who were either starting treatment with deferasirox at the time of enrollment or currently under treatment with deferasirox up to 12 months prior to enrollment were observed in this study. In order to assess the primary end point, only patients with available baseline values for serum creatinine ( $\mathrm{SCr}$ ) and alanine aminotransferase (ALT) measured up to a maximum period of 45 days prior to the first dose of deferasirox were included. Exclusion criteria included the following: patients with non-transfusional hemosiderosis and patients treated with deferasirox in an interventional clinical trial. Patients (or parents/guardians) provided written informed consent prior to any screening procedures. The study was conducted according to the ethical principles of the Declaration of Helsinki.

\subsection{Assessments}

The primary objective was to evaluate the long-term safety of deferasirox treatment in adult and pediatric patients aged $\geq 2$ years with chronic transfusional iron overload in actual practice setting. The two coprimary end points were the proportion of patients (within a maximum of 3 years of observation) with the following: (1) at least one increase in $\mathrm{SCr}$, defined as $>33 \%$ above baseline and the age-adjusted upper limit of normal (ULN) on at least two consecutive measurements ( $\geq 7$ days apart); and (2) at least one increase in ALT, defined as $>5 \times U L N$ on at least two consecutive measurements ( $\geq 7$ days apart). A secondary objective was to evaluate the long-term efficacy of deferasirox as measured by serum ferritin (SF) levels over a period of 3 years. Secondary objectives also included the evaluation of safety as measured by adverse events (AEs), laboratory parameters, renal histology, cardiac magnetic resonance (CMR), electrocardiograms (ECGs), echocardiography, vital signs, audiometry, and ophthalmology assessments.

\subsection{Statistical evaluations}

The full analysis set (FAS) consisted of all patients who received at least one dose of deferasirox during the study. The FAS was used for the statistical analysis of SF levels. The safety set consisted of all patients who received at least one dose of deferasirox during the study and had at least one post-baseline safety assessment. The primary end point was performed based on the safety set. Data are presented in mean $\pm S D$ or median (range).

\section{Results}

\subsection{Patient demographics and clinical characteristics}

The majority of the patients included in the study were diagnosed with $\beta$ thalassemia $(n=49), \operatorname{SCD}(n=31)$, MDS $(n=21)$, and other transfusion-dependent anemias $(n=19)$. The mean $( \pm$ SD) age was $28.9 \pm 29.0$ in the study population, $7.5 \pm 4.2$ years in patients $<18$ years $(n=69)$ and $57.9 \pm 22.1$ years in patients 
Table 2. Overall patient disposition by age group.

\begin{tabular}{|c|c|c|c|}
\hline Disposition reason & $\begin{array}{l}<18 \text { years } \\
(n=69) \\
n(\%)\end{array}$ & $\begin{array}{l}\geq 18 \text { years } \\
(n=51) \\
n(\%)\end{array}$ & $\begin{array}{l}\text { All patients } \\
(n=120) \\
n(\%)\end{array}$ \\
\hline \multicolumn{4}{|l|}{ Patients treated } \\
\hline Completed study & $45(65.2)$ & $6(11.8)$ & $51(42.5)$ \\
\hline Discontinued study, $n$ (\%) & $24(34.8)$ & $45(88.2)$ & $69(57.5)$ \\
\hline Subject's condition no longer requires study drug & $7(10.1)$ & $16(31.4)$ & $23(19.2)$ \\
\hline Adverse event(s) & $2(2.9)$ & $13(25.5)$ & $15(12.5)^{\mathrm{a}}$ \\
\hline Consent withdrawal & $9(13.0)$ & $4(7.8)$ & $13(10.8)$ \\
\hline Lost to follow-up & $6(8.7)$ & $2(3.9)$ & $8(6.7)$ \\
\hline Death $^{\mathbf{b}}$ & 0 & $7(13.7)$ & $7(5.8)$ \\
\hline Protocol deviation & 0 & $2(3.9)$ & $2(1.7)^{c}$ \\
\hline Disease progression & 0 & $1(2.0)$ & $1(0.8)$ \\
\hline \multicolumn{4}{|c|}{$\begin{array}{l}\text { a Disposition for an additional seven patients who discontinued due to both an adverse event and } \\
\text { death is accounted for under the most severe outcome (death). }\end{array}$} \\
\hline \multicolumn{4}{|c|}{$\begin{array}{l}\text { b Only on-treatment deaths from day } 1 \text { to the day of last study drug }+30 \text { days are provided; } 1 \\
\text { additional death occurred during the study; this patient discontinued due to a protocol deviation } \\
\text { and died within } 30 \text { days of stopping treatment. }\end{array}$} \\
\hline \multicolumn{4}{|c|}{$\begin{array}{l}\text { 'One patient who discontinued due to a protocol deviation died within } 30 \text { days after stopping } \\
\text { treatment (on-treatment death). }\end{array}$} \\
\hline
\end{tabular}

$\geq 18$ years $(n=51)$. The median number of blood transfusions before entering into the study was $30.0(<18$ years, $33.0 ; \geq 18$ years, 29.0), with the majority of patients requiring bi-weekly $(16.7 \%)$ or monthly (62.5\%) blood transfusions (Table 1).

\subsection{Patient disposition}

The first patient first visit was July 2011, and the last patient last visit was October 2015. A total of 120 patients with transfusional hemosiderosis were enrolled ( $<18$ years, $n=69$ and $\geq 18$ years, $n=51$ ). The FAS included all 120 patients, and the safety analysis set included 117 patients. Sixty-nine patients (57.5\%) discontinued the study. Fifteen (12.5\%) of these discontinuations were related to AEs and more commonly observed in adult patients (25.5\%) compared to pediatric patients (2.9\%). The reasons for study discontinuation are presented in Table 2.

\subsection{Exposure to deferasirox treatment}

The median average of actual dose of deferasirox was $23.3 \mathrm{mg} / \mathrm{kg} /$ day (range, 2.3-41.3). The median duration of deferasirox exposure was 29.9 months (range, 0.839.2). The median dose of deferasirox with relation to blood intake in patients $\geq 18$ years was 12.5 and $23.7 \mathrm{mg} / \mathrm{kg} /$ day with low $(<7 \mathrm{~mL} / \mathrm{kg} /$ day) and intermediate $(7-14 \mathrm{~mL} / \mathrm{kg} /$ day) transfusional burden, respectively. Based on serum ferritin level, deferasirox was adjusted or interrupted according to the local label.

\subsection{Dose reductions or interruptions}

In the overall population, 55 patients (47.0\%) had dose reductions or interruptions. The mean number of dose reductions or interruptions was 1.7 in all patients. The most common reasons for patients with at least one dose reduction or interruption were AEs (27.4\%) and others (20.5\%) (including, but were not limited to, dose adjustment for weight, improvement/decrease in SF, drug unavailability, investigator decision, and patients discontinued taking drug therapy due to an error).

\subsection{Prior iron chelation therapy}

Overall, $54.2 \%$ of patients ( $n=65)$ were chelation-naïve and $45.8 \% \quad(n=55)$ received prior iron chelation therapy. Evaluable chelation-naïve patients received a lower average actual dose $(\mathrm{mg} / \mathrm{kg} /$ day, mean $\pm \mathrm{SD})$ of deferasirox compared to patients receiving prior iron chelation therapy $(<18$ years, $23.8 \pm 5.2$ vs. $27.6 \pm 7.4$; $\geq 18$ years, $15.4 \pm 7.7$ vs. $20.3 \pm 9.7$ ).

\subsection{Safety parameters}

\subsubsection{Adverse events}

Overall, 40 patients (34.2\%) had AEs suspected to be related to study drug. The most common AEs (>3\% in the overall patient population) are presented in Figure 1. Deferasirox-related AEs gradually decreased over time (Figure 2(A)) for patients continuing on study.

Serious adverse events, suspected to be related to study drug, were reported in five patients (4.3\%); the most frequently reported being gastrointestinal hemorrhage $(n=2)$. A total of 99 patients $(84.6 \%)$ had at least $1 \mathrm{AE}$ regardless of relationship to the study drug. Overall incidence of AEs regardless of relationship with deferasirox also decreased over time (Figure 2(B)) for patients continuing on study. The most common AEs were gastrointestinal disorders, $(43.6 \% ; n=51)$ and infections and infestations $(43.6 \%$; $n=51$ ). Adverse events occurring in $>10 \%$ of patients were vomiting $(16.2 \%)$, pyrexia $(15.4 \%)$, diarrhea (13.7\%), cough (12.8\%), abdominal pain (12.0\%), head 


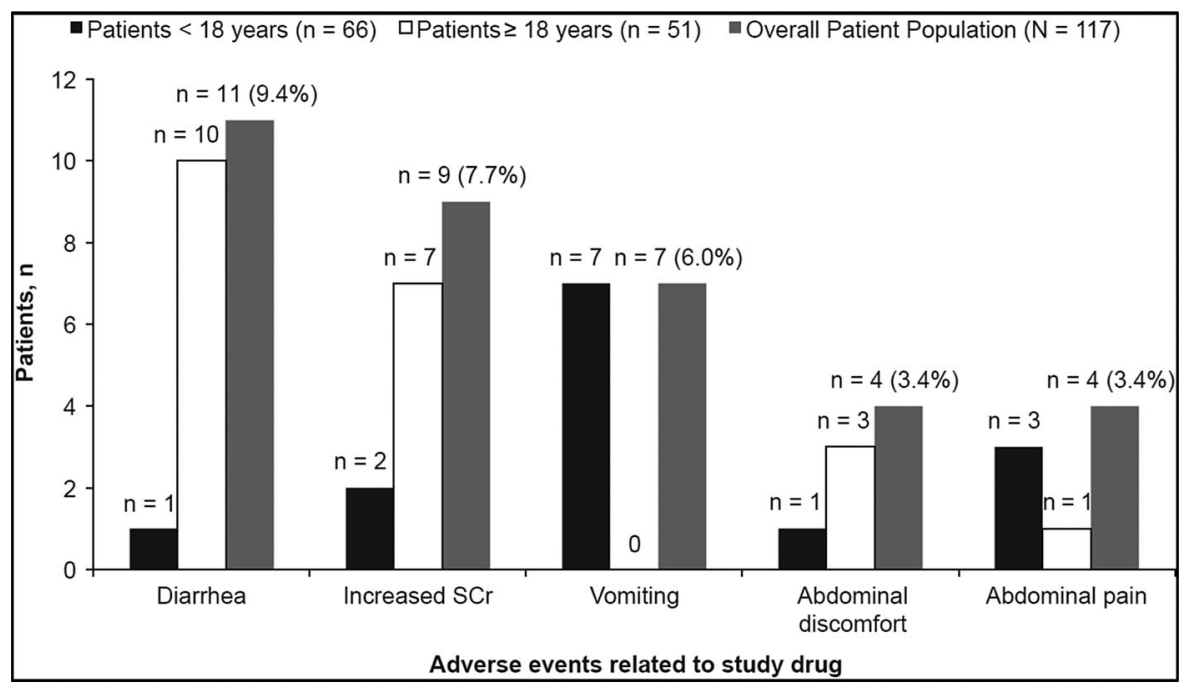

Figure 1. Adverse events ( $>3 \%$ in the overall patient population) suspected to be related to the study drug. Note: $\mathrm{SCr}$, serum creatinine.

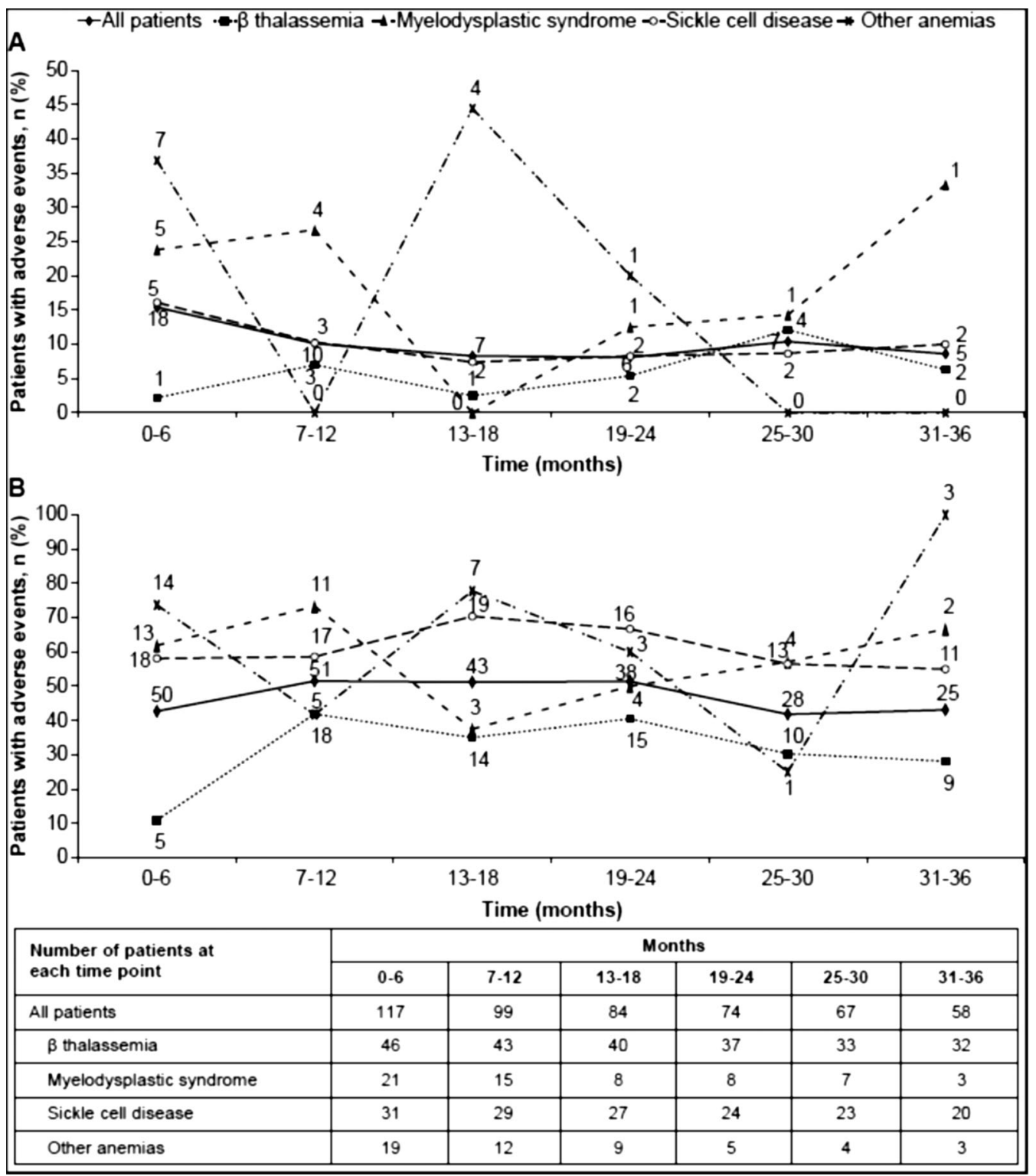

Figure 2. Number of patients with adverse events over time $(n=117)$. (A) Patients with adverse events suspected to be related to deferasirox over time (by underlying disease). (B) Patients with adverse events regardless of relationship to deferasirox over time (by underlying disease). 
Table 3. Patients with increase in serum creatinine or alanine aminotransferase.

\begin{tabular}{|c|c|c|c|c|}
\hline Criteria & $\begin{array}{c}<18 \\
\text { years } \\
n=66\end{array}$ & $\begin{array}{c}\geq 18 \\
\text { years } \\
n=51\end{array}$ & $\begin{array}{c}\text { All } \\
\text { patients } \\
n=117\end{array}$ & $95 \% \mathrm{Cl}$ \\
\hline $\begin{array}{l}\text { Patients with at least } 1 \text { episode of SCr increase from baseline }>33 \% \text { and }>\text { age-adjusted ULN at } 2 \\
\text { consecutive visits ( } \geq 7 \text { days apart) }\end{array}$ & $8(12.1)$ & $6(11.8)$ & $14(12.0)$ & $\begin{array}{l}7.1 \\
19.2\end{array}$ \\
\hline Patients with at least 1 episode of ALT $>5 \times U L N$ at 2 consecutive visits ( $\geq 7$ days apart) & $1(1.5)$ & 0 & $1(0.9)$ & $0.0,5.2$ \\
\hline
\end{tabular}

ache $(10.3 \%)$, and upper respiratory tract infection (10.3\%). Most patients had normal auditory and ocular results during the study. For audiometric test results, a 7-year-old male patient had three clinically significant abnormalities (moderately severe sensorineural affection at high frequencies, bilaterally lost acoustic reflexes, and mild bilateral sensorineural hearing loss at high frequencies) and an AE of neurosensory deafness, which was suspected to be related to study drug, was reported for the same patient. The patient withdrew consent and did not complete the study. Two patients had clinically significant abnormalities for ocular examinations. One 7-year-old female patient had the most extreme post-baseline results of two possible inferior visual field defects, and the second 48-year-old female patient had a baseline result of sickle-cell retinopathy and vitreous hemorrhage in the right eye. The two patients did not complete the study, as their condition no longer required the study drug.
Eight on-treatment deaths (6.8\%) were reported, all in patients $\geq 18$ years, mainly due to neoplasms (acute leukemia, $n=1$; acute lymphocytic leukemia, $n=1$ ) and gastrointestinal complications (gastrointestinal hemorrhage, $n=1$; intestinal ischemia, $n=1$ ). None of these deaths were suspected to be related to the study drug.

\subsubsection{Adverse events leading to discontinuation of study drug. Adverse events leading to discontinuation of the study drug occurred in 22 patients (18.8\%). Of these patients, 11 (9.4\% [17.6\% vs. $3.0 \%$ for $\geq 18$ years vs. $<18$ years]) had AEs suspected to be related to the study drug. The most common AEs (>2\%) leading to discontinuation regardless of relationship with study drug were increased $\mathrm{SCr}(3.4 \%)$ and diarrhea (2.6\%), both of which occurred only in patients aged $\geq 18$ years.}

\subsubsection{Laboratory parameters}

3.6.2.1. Serum creatinine. Increase in $\mathrm{SCr}>33 \%$ above baseline and the age-adjusted ULN in at least two

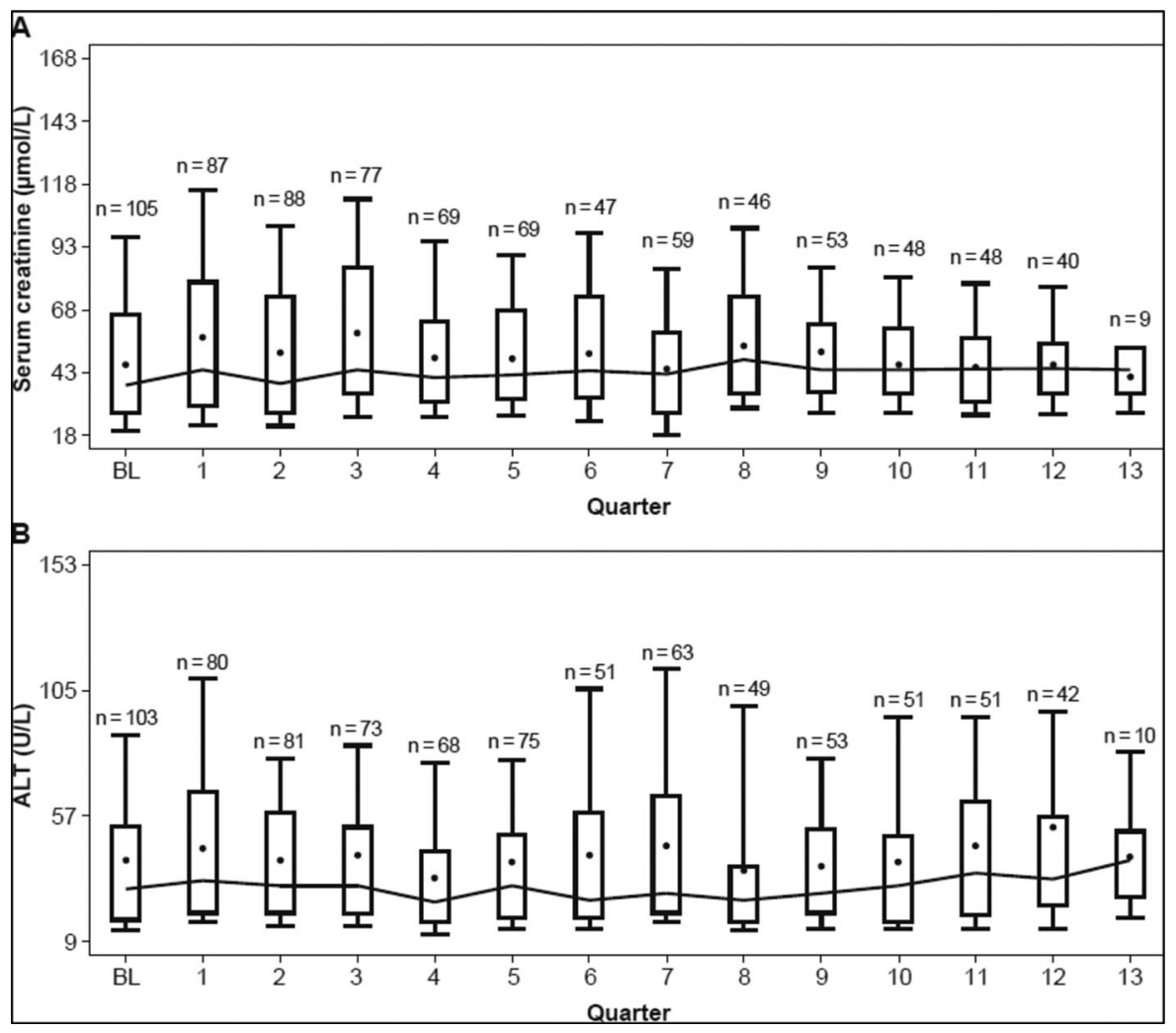

Figure 3. Distribution of $(A)$ serum creatinine and (B) alanine aminotransferase over time. Notes: Boxes indicate median \pm 25 th $/ 75$ th centile. The means are presented as dots, and medians of time points are connected over time. ALT, alanine aminotransferase. 
consecutive measurements $(\geq 7$ days apart) was observed in 14 patients (12\%; 95\% confidence interval [Cl], 7.1-19.2) with MDS $(n=3), \operatorname{SCD}(n=7)$, and other anemias $(n=4)$ (Table 3$)$. Of these a higher proportion of patients aged $<18$ years $(78.8 \%)$ had $\mathrm{SCr}$ values $\leq$ ULN during treatment as compared to patients with $\geq 18$ years $(37.3 \%)$. In the overall study population, the total $\mathrm{SCr}$ by quarters showed non-progressive, stable $\mathrm{SCr}$ values over the 3 years (Figure 3(A)). Due to increased $\mathrm{SCr}$, five patients had dose adjustments or interruptions, and four patients discontinued, which were suspected to be related to drug. During the study, in the overall population, 55 patients had a confirmed creatinine clearance $(\mathrm{CrCl}) \geq 90 \mathrm{~mL} / \mathrm{min}$, and 9 patients had confirmed $\mathrm{CrCl}$ of $60-<90 \mathrm{~mL} /$ min on 2 consecutive measurements ( $\geq 7$ days apart).

\subsubsection{Alanine aminotransferase}

Of the eight patients, $<18$ years of age who presented with single events of elevated ALT $>5 \times$ ULN and $>2 \times$ baseline during the study period, four had an underlying diagnosis of $\beta$ thalassemia and four had SCD. None of the patients discontinued study drug due to elevated liver function tests (LFTs); reasons for the increased LFTs were not apparent. Six of the eight patients $(75 \%)$ completed the study, despite transient events of increased ALT, and two of the eight patients ended the study because the investigator judged deferasirox as no longer necessary. All pediatric patients except one were chelation naïve while starting deferasirox.

Of the two patients $(1.7 \%)$ aged $\geq 18$ years who exhibited single events of elevated ALT $(>5 \times$ ULN and $>2 \times$ baseline), one had an underlying diagnosis of MDS and ended the study due to increased SCr. The other patient received a stem cell transplant with curative intent for the underlying chronic lymphocytic leukemia and this patient ended the study because deferasirox was deemed by the investigator as no longer needed.

Increase in ALT >5 $\times$ ULN in at least two consecutive measurements ( $\geq 7$ days apart) was observed in one patient $(0.9 \% ; 95 \% \mathrm{Cl}, 0.0-5.2)$ with $\beta$ thalassemia (baseline ALT missing) (Table 3). In the overall population, the total ALT showed no apparent trend, with some fluctuations over time during the 3 years (Figure 3(B)). Increased ALT lead to dose adjustments or interruptions in two patients $(1.7 \% ; \beta$ thalassemia $[n=2])$ aged $<18$ years. None of the patients discontinued because of increased ALT.

\subsection{Long-term efficacy of deferasirox}

In the overall patient population, mean SF levels decreased from $2373 \mu \mathrm{g} / \mathrm{L}$ (range, 298-8317) to $2110 \mu \mathrm{g} / \mathrm{L}$ (range, 151-9954) from baseline to end of study. In the overall population, $>50 \%$ of the patients had decreased SF compared to baseline with a mean change of $-223 \mu \mathrm{g} / \mathrm{L}$. In patients aged $<18$ years, mean SF levels decreased from 2445 (range, 2988317 ) to 2170 (range, 151-9954), whereas in patients $>18$ years of age, mean SF levels decreased from 2246 (range, 490-7500) to 2004 (range, 317-8250). A higher proportion of the overall patient population had SF values $\leq 1000 \mu \mathrm{g} / \mathrm{L}$ at the end of the observation period $(27.5 \%)$ than at the start of deferasirox treatment (13.3\%) (Figure 4).

\section{Discussion}

The observational study reported the long-term safety of deferasirox in adult and pediatric patients aged $\geq 2$ years with chronic transfusional iron overload at enrollment. In this study, $52.7 \%$ of patients discontinued treatment. The overall duration of deferasirox treatment in the present 3-year study was 29.9 months. The total time on study drug was 26.9 months when accounting for reported dose interruptions. Thus, patients received a daily dose of deferasirox in $90 \%$ of days on chelation treatment indicating an acceptable overall safety profile.

In this study, there was a low discontinuation rate due to AEs, particularly in patients aged $<18$ years indicating deferasirox was manageable in pediatric patients as well as in overall patient population. Although no direct comparison can be made across clinical trials, it seems that the rate of completion of patients treated with deferasirox in this observational trial is in line with the results obtained in the 4-year extension of a phase 2 study involving pediatric and adult patients with transfusional hemosiderosis.

The highest percentage of pediatric patients in the present study was in the $\beta$ thalassemia major and the second highest in SCD, which is expected for the most common red blood cell disorders diagnosed in infancy. In this study, the majority of the patients were Caucasians (67.5\%), followed by Blacks (22.5\%), Asians (5.8\%), and others (3.3\%). This distribution is in line with the general association of diagnosis of thalassemia and MDS being more prevalent among Caucasians and SCD being more prevalent in Black patients.

The most frequent AEs reported during the treatment with deferasirox in adult and pediatric patients were related to $\mathrm{Gl}$ disturbances in about $26 \%$ of patients (mainly nausea, vomiting, diarrhea, or abdominal pain). Notable increases in $\mathrm{SCr}$ and liver function tests were observed in some patients, and those increases were consistent with the known safety profile of deferasirox. In deferasirox registration studies [9-11], which included patients with transfusional siderosis, elevations in $\mathrm{SCr}$ of $>33 \%$ on $\geq 2$ consecutive visits, sometimes $>$ ULN, occurred in about $36 \%$ of patients. In the present study, the proportion 


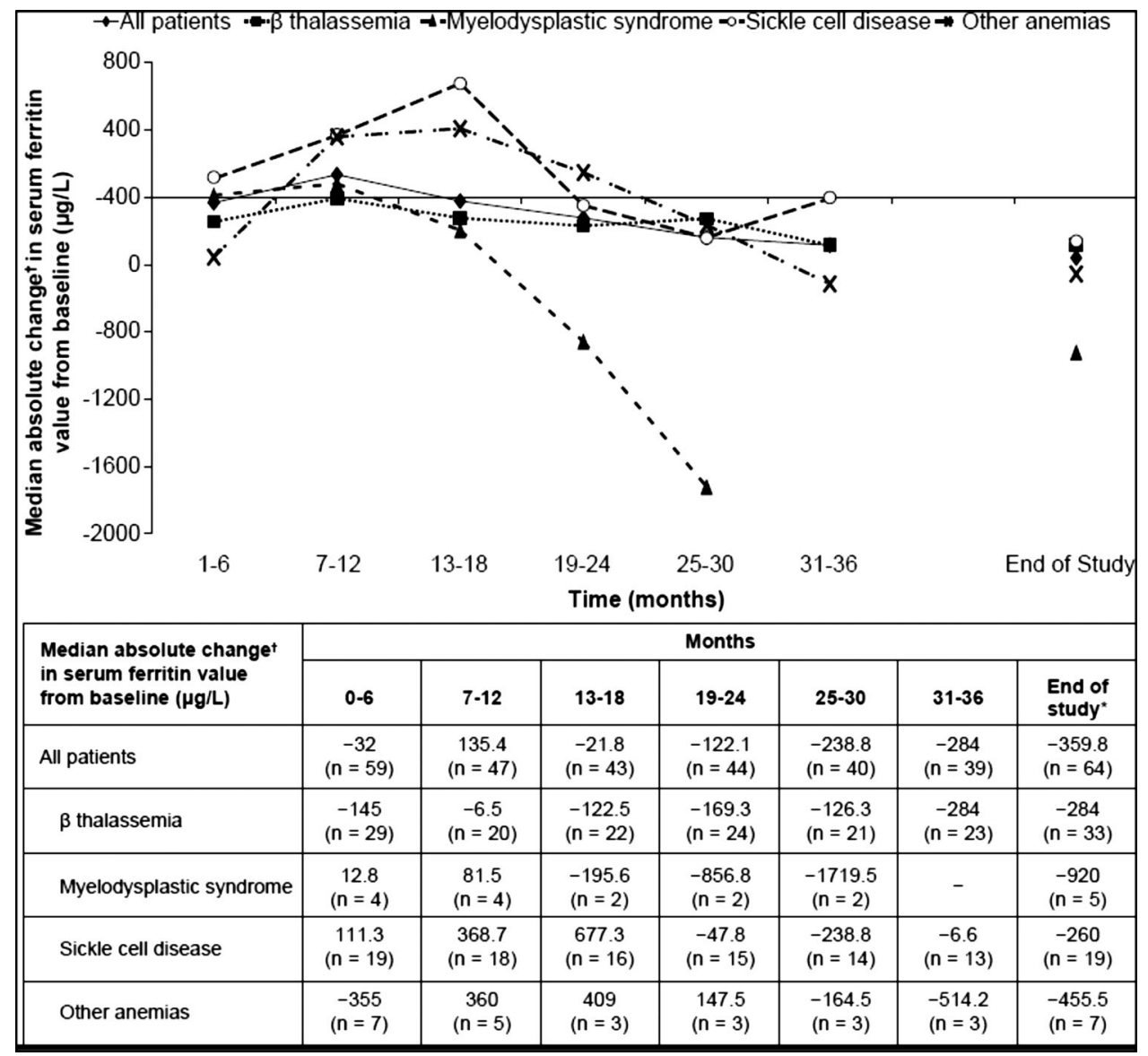

Figure 4. Median absolute change in serum ferritin $(\mu \mathrm{g} / \mathrm{L})$ values from baseline over time by the underlying disease. Notes: ${ }^{\dagger} \mathrm{Absol}-$ ute change refers to change of serum ferritin values at each time point from baseline. *End of study refers to the last available postbaseline serum ferritin value.

of patients with $\mathrm{SCr}>\mathrm{ULN}$ at two consecutive visits at least 7 days apart was $12 \%$ during the 3 -year observation period. Furthermore, the total $\mathrm{SCr}$ in all patients showed only a slight increase in $\mathrm{SCr}$ levels, remaining stable over time during the 3-year observation period. An evaluation of the change of renal function in the adult population in the present study is limited by the relatively high number of missing values $(n=$ $40,78.4 \%$ ). It is of note that renal safety in the study population may be attributable to various factors and not limited to iron chelation treatment. Renal abnormalities in patients with transfusion-dependent siderosis were previously reported in the literature and suggest that iron overload and anemia are likely to contribute to renal dysfunction $[12,13]$. A recent study evaluating long-term renal safety in Italian patients who participated in deferasirox registration studies, indicated no progressive or late change in renal function for patients exposed to deferasirox and other chelation treatment for up to 13 years [14].

The renal safety was also supported by a slight initial decrease in $\mathrm{CrCl}$, which remained stable in most patients throughout the study and is consistent with the data from previous studies that have shown an early initial drop in $\mathrm{CrCl}$, followed by stabilization [15]. Deferasirox has also been shown to be associated with a mild reversible hemodynamic effect on renal function in patients receiving short-term and longterm treatments [16]. Renal parameters remained stable indicating no further decline in renal function over time. The findings observed from the current study were consistent with the 5-year renal data from the pivotal registration study, indicated no progressive worsening of the renal function over time on the basis of $\mathrm{SCr}$ and $\mathrm{CrCl}$ monitoring [17].

In a 5-year analysis within the deferasirox program, elevations of transaminases $>10 \times$ ULN were uncommon (0.3\%). Furthermore, there was an initial increase in ALT levels during the first 2 years of deferasirox treatment following a downward trend for the remainder of the study [17]. The increase in ALT could potentially be attributed to iron overload, which is known to increase liver enzyme levels, particularly in patients with high liver iron concentration due to continued transfusion dependence [18]. There was no apparent relationship between deferasirox dose and liver transaminase increases [17]. In this observational study, ALT levels $>5 \times$ ULN in at least two consecutive post-baseline measurements at least 7 days apart was observed in one patient and no patients in the study population discontinued due to increases in ALT. 
A lower deferasirox median dose in relation to blood intake was observed mainly in adult patients with low transfusional burden compared to adult patients with intermediate burden. This observation suggests that dose adjustments are either multifactorial taking into account other clinical parameters or that patient may not be adequately dose adjusted as the transfusional iron burden increases over time.

Most of the patients had normal auditory and ocular results during the study, with few patients having clinically significant auditory or ocular abnormalities. Of the 120 observed patients in this study, one pediatric patient discontinued the study with neurosensory affection of hearing. Most other observed impairments of hearing in the pediatric population were conductive, transitory, and assessed not to be related to the study treatment.

A 4-year extension study of the phase 2 study in an SCD patient population demonstrated a median absolute change in SF from the start of treatment with deferasirox to the end of study and its $95 \% \mathrm{Cl}$ of $-246 \mu \mathrm{g} / \mathrm{L}$ $(-530 ; 402)$ in patients receiving deferasirox throughout the study [15]. The analysis of SF levels in the 5year observational study, in a mixed population of pediatric patients with iron overload including SCD, also demonstrated a better reduction in SF of $-576 \mu \mathrm{g} / \mathrm{L}$ [19]. During this study, a proportion of patients with SCD $(>50 \%)$ had an initial increase in SF at 6 months before they start to have a negative balance. Overall, the SF was moderately reduced from baseline to the end of the study for the majority of patients.

Approximately, $43 \%$ of patients completed the global 3-year post-authorization safety study, with a 3-year dropout rate of $12.5 \%$ due to AEs in all patients and $2.9 \%$ in patients aged $<18$ years. None of the five deaths occurring during the study were observed in pediatric patients or suspected to be related to study treatment. Thus, the data further add evidence that chronic iron chelation therapy with deferasirox is manageable in a pediatric patient population, as well as in the overall patient population. Notable increases in $\mathrm{SCr}$ and liver function tests were observed in some patients, and those increases were consistent with the known safety profile of deferasirox.

Limitations of this study were high discontinuation rate $(57.5 \%)$ and usage of SF levels to adjust the deferasirox dosage instead of using T2-MRI, which is more accurate.

In conclusion, the data from this 3-year, non-interventional study of deferasirox in adult and pediatric patients with chronic transfusional iron overload were consistent with the known safety profile of deferasirox with no unexpected or accumulative events during observation. Regular monitoring and an adjusted deferasirox dosing strategy per local labels allow effective management of most AEs for long-term chelation and control of transfusional iron in the majority of patients in clinical practice.

\section{Acknowledgments}

We thank Haritha Nekkanti (Novartis Healthcare Pvt Ltd) for providing medical editorial assistance.

\section{Disclosure statement}

B. Xicoy reports honoraria from Novartis Pharmaceuticals Corporation and Celgene. A. Bruederle, A. Amin, and G. Gilotti are full-time employees of Novartis Pharmaceuticals Corporation. B. Inusa, D. Beneitez, M. Duran Neito, and M. Elalfy have nothing to disclose. A El-Beshlawy reports research funding from Novartis Pharmaceuticals Corporation and ApoPharma Inc.

\section{Funding}

This study was funded by Novartis Pharma AG.

\section{ORCID}

David Beneitez Pastor (D) http://orcid.org/0000-0002-65416600

\section{References}

[1] Karami $H$, Kosaryan $M$, Amree $A H$, et al. Combination iron chelation therapy with deferiprone and deferasirox in iron-overloaded patients with transfusion-dependent $\beta$-thalassemia major. Clin Pract. 2017;7:912.

[2] Cerchione C, Cerciello G, Avilia S, et al. Management of iron overload in myelodysplastic syndromes: combined deferasirox and deferoxamine in a patient with liver disease. Blood Transfus. 2016;24:1-4.

[3] Cappellini MD. Exjade(R) (deferasirox, ICL670) in the treatment of chronic iron overload associated with blood transfusion. Ther Clin Risk Manag. 2007;3:291299.

[4] Osborne RH, De Abreu Lourenço R, Dalton A, et al. Quality of life related to oral versus subcutaneous iron chelation: a time trade-off study. Value Health. 2007;10:451-456.

[5] Delea TE, Edelsberg J, Sofrygin O, et al. Consequences and costs of noncompliance with iron chelation therapy in patients with transfusion-dependent thalassemia: a literature review. Transfusion. 2007;47:19191929.

[6] Taher AT, Origa R, Perrotta S, et al. New film-coated tablet formulation of deferasirox is well tolerated in patients with thalassemia or lower-risk MDS: results of the randomized, phase II ECLIPSE study. Am J Hematol. 2017;92:420-428.

[7] Novartis Pharmaceuticals Corporation. EXJADE ${ }^{\circledR}$ (deferasirox) US prescribing information; [cited 2017 Mar 21]. Available from: http://www.pharma.us.novartis.com/ product/pi/pdf/exjade.pdf

[8] Novartis Pharmaceuticals UK Ltd. Summary of product characteristics - EXJADE 125 mg, 250 mg, 500 mg dispersible tablets; [cited 2017 Mar 21]. Available from: http:// www.medicines.org.uk/emc/medicine/18805/SPC/ 
[9] Piga A, Galanello R, Forni GL, et al. Alberti, randomized phase II trial of deferasirox (Exjade, ICL670), a oncedaily, orally-administered iron chelator, in comparison to deferoxamine in thalassemia patients with transfusional iron overload. Haematologica. 2006;91:873-880.

[10] Cappellini MD, Cohen A, Piga A, et al. A phase 3 study of deferasirox (ICL670), a once-daily oral iron chelator, in patients with beta-thalassemia. Blood. 2006;107:34553462.

[11] Vichinsky E, Onyekwere O, Porter J, et al. Deferasirox in sickle cell investigators. A randomized comparison of deferasirox versus deferoxamine for the treatment of transfusional iron overload in sickle cell disease. $\mathrm{Br} \mathrm{J}$ Haematol. 2007;136:501-508.

[12] Sumboonnanonda A, Malasit $P$, Tanphaichitr VS, et al. Renal tubular function in $\beta$-thalassemia. Pediatr Nephrol. 1998;12:280-283.

[13] Aldudak B, Karabay Bayazit A, Noyan A, et al. Renal function in pediatric patients with $\beta$-thalassemia major. Pediatr Nephrol. 2000;15:109-112.

[14] Origa R, Piga A, Tartaglione I, et al. Similar trends in renal function as measured by serum creatinine during longterm iron chelation treatment with or without deferasirox in patients with transfusional hemosiderosis. EHA (Abs: P288); [cited 2017 Sep 14]. Available from: https://learningcenter.ehaweb.org/eha/2017/22nd/ 181575/raffaella.origa.similar.trends.in.renal.function.as. measured.by.serum.html

[15] Vichinsky E, Bernaudin F, Forni G, et al. Long-term safety and efficacy of deferasirox (Exjade ${ }^{\oplus}$ ) for up to 5 years in transfusional iron overloaded patients with sickle cell disease. Br J Haematol. 2011;154:387397.

[16] Piga A, Fracchia S, Lai ME, et al. Deferasirox effect on renal haemodynamic parameters in patients with transfusion-dependent $\beta$ thalassaemia. $\mathrm{Br} J$ Haematol. 2015;168:882-890.

[17] Cappellini MD, Bejaoui M, Agaoglu L, et al. Iron chelation with deferasirox in adult and pediatric patients with thalassemia major: efficacy and safety during five years' follow-up. Blood. 2011;118:884-893.

[18] Jensen PD, Jensen FT, Christensen T, et al. Relationship between hepatocellular injury and transfusional iron overload prior to and during iron chelation with desferrioxamine: a study in adult patients with acquired anemias. Blood. 2003;101:91-96.

[19] Vichinsky E, El-Beshlawy A, Al Zoebie A, et al. Long-term safety and efficacy of deferasirox in young pediatric patients with transfusional hemosiderosis: results from a 5-year observational study (ENTRUST). Pediatr Blood Cancer. 2017;64:e26507. doi:10.1002/pbc.26507. [Epub ahead of print]. 